\title{
Silver Nanoparticles: Green Synthesis, Characterization, and Their Usage in Determination of Mercury Contamination in Seafoods
}

\author{
Muhammad Ahad Ahmed, ${ }^{1}$ Najmul Hasan, ${ }^{2}$ and Shaikh Mohiuddin ${ }^{1}$ \\ ${ }^{1}$ Department of Chemistry, Faculty of Science, University of Karachi, Karachi 75270, Pakistan \\ ${ }^{2}$ Department of Microbiology, Faculty of Science, University of Karachi, Karachi 75270, Pakistan \\ Correspondence should be addressed to Najmul Hasan; najam.edu.pak@gmail.com
}

Received 22 October 2013; Accepted 26 December 2013; Published 4 February 2014

Academic Editors: D. Wang and J. Zhan

Copyright (C) 2014 Muhammad Ahad Ahmed et al. This is an open access article distributed under the Creative Commons Attribution License, which permits unrestricted use, distribution, and reproduction in any medium, provided the original work is properly cited.

\begin{abstract}
We demonstrate that silver nanoparticles undergo an interaction with $\mathrm{Hg}^{2+}$ found in traces. The PEG-PVP-stabilized Ag nanoparticles were successfully synthesized via a reduction approach and characterized with surface plasmon resonance UV/Vis spectroscopy. By utilizing the redox reaction between $\mathrm{Ag}$ nanoparticles and $\mathrm{Hg}^{2+}$, and the resulted decrease in UV/Vis signal, we develop a colorimetric method for detection of $\mathrm{Hg}^{2+}$ ion. A linear and inversely proportional relationship was found between the absorbance intensity of the $\mathrm{Ag}$ nanoparticles and the concentration of $\mathrm{Hg}^{2+}$ ion over the range from $10 \mathrm{ppm}$ to 1 ppm at absorption on $411 \mathrm{~nm}$. The detection limit for $\mathrm{Hg}^{2+}$ ions in homogeneous aqueous solutions is estimated to be $1 \mathrm{ppm}$. This system shows excellent selectivity for $\mathrm{Hg}^{2+}$. The results found have potential implications in the development of new colorimetric sensors for easy and selective detection and monitoring of mercuric ions in aqueous solutions. The proposed method was successfully applied to quantify the amount of mercury in seafood.
\end{abstract}

\section{Introduction}

Pollution is the introduction of contaminants into a natural environment resulting in instability, disorder, harm, or discomfort to the ecosystem including physical systems and living organisms. Among the pollutants and particularly among heavy metals, mercury is one of the most commonly encountered toxic pollutant in the environment which may be a result of natural processes and emissions from coal burning power plants and gold mining [1]. Similarly, in aqueous solution, bacteria can transform water-soluble mercuric ion $\left(\mathrm{Hg}^{2+}\right)$ into methylmercury, which is the most common form of mercury in fish, and subsequently bioaccumulates through the food chain [2]. Methylmercury is a potent neurotoxin known to cause health problems such as sensory, motor, and neurological damage. It is particularly dangerous for children, because it can cause developmental delays [3].

Although the traditional instrumental techniques, such as absorption spectroscopy, cold vapor atomic fluorescence spectrometry, and gas chromatography, give the direct and quantitative detection of $\mathrm{Hg}^{2+}$ concentration [4,5], it is highly desirable to develop facile and quick methods for measuring the level of this detrimental metallic ion in the environment with high sensitivity and selectivity.

To date, several methods providing the optical feedback for the detection of $\mathrm{Hg}^{2+}$ based upon fluorophores [6-10] chromogenic redox based fluorescent method [11], chromophores [12], polymer [13], and noble metal-based probes [14-18] have been developed. In this regard, among noble-metal nonmaterials, silver nanoparticles (SNPs) have received considerable attention due to their attractive physicochemical properties. The surface plasmon resonance and large effective scattering cross section of individual silver nanoparticles make them ideal candidates for molecular labeling [19].

To avoid complicated instrumentation or sample preparation, the objective of this paper is to present experimental 
results using silver nanoparticles as source of determination of pollutant in marine food. We hope to obtain systematic results regarding the formation of nanosized silver colloids and their usage to determine mercury contamination in fish food quantitatively. In this paper, we present a method with colorimetric quantitative recognition of $\mathrm{Hg}^{2+}$ with excellent selectivity and sensitivity based on an erosion reaction of PVP-stabilized Ag nanoparticles in aqueous media. The easy synthesis and high stability of the PEG-PVP-stabilized Ag nanoparticle allow the method to be very simple and easy to implement.

\section{Material and Methods}

The present method was designed to be nonhazardous, environment friendly, easy to use, sensitive, rapid, and simple sample preparation for the optimal sensing and detection of polluting metals.

2.1. Chemicals and Materials. All chemicals were of analytical grade and were used as received without further purification. Silver nitrate $\left(\mathrm{AgNO}_{3}\right)$ (Merck, Karachi, Pakistan), Stock solution of mercury (Merck, $1000 \mathrm{ppm}$ ), and nitric acid $\left(\mathrm{HNO}_{3}\right)($ Merck, Karachi, Pakistan) were of analytical reagent grade used for solution preparation. Polyethyeleneglycol (PEG6000) powder 99\% and polyvinylpyrrolidone (PVP K30) were purchased from local vendors. All the other solutions were freshly made for all the experimental procedures in this work. Double distilled water was used for all solutions preparation, and all glassware is cleaned with aqua regia and thoroughly rinsed with ultrapure water prior to use.

2.2. Instrumentation. For maintaining temperature requirement, Memmert water bath tub (Japan) was used. A UVvisible Shimadzu 1650PC spectrophotometer with UV Probe software, analytical balance (Sartorious TE2145), Hotplate stirrer (Lab Comapnion HP 3000L), and Shaker (Labnet Orbit1000) was used in the research work. Throughout the work, only amber glass flasks were used to avoid light effect on the solutions of $\mathrm{AgNO}_{3}, \mathrm{PEG}, \mathrm{SNPs}, \mathrm{PVP}$, and $\mathrm{Hg}^{2+}$ standards and samples solutions.

2.3. Experimental Conditions. The SNPs development was carried out at $100^{\circ} \mathrm{C}$ temperature for 60 minutes under temperature maintained water bath tub. The precursor, standard, and sample solutions were all prepared in double distilled water.

\section{Analytical Procedure}

3.1. Solutions Preparation. A solution of $0.1 \mathrm{M} \mathrm{AgNO}_{3}$ was prepared by dissolving $1.6978 \mathrm{~g}$ in $100 \mathrm{~mL}$ of double distilled water. The model reducing agent used was PEG-6000, which is an example of a good reducing agent whereas PVP was used as stabilization materials in this study. PEG-6000 and PVP were prepared by separately dissolving in double distilled water at room temperature using a magnetic stirrer and water bath at $80^{\circ} \mathrm{C}$. A $20 \%(\mathrm{w} / \mathrm{v})$ of homogenous PEG-6000 stock solution was prepared by adding PEG powder to $500 \mathrm{~mL}$ reagent bottle containing ultrapure water and agitated with a magnetic stirring at $100 \mathrm{rpm}$ for 30 minutes at room temperature. The PVP 20\% (w/v) was prepared by adding PVP powder to $500 \mathrm{~mL}$ reagent bottle containing ultrapure water and shaking on water bath shaker at $200 \mathrm{rpm}$ for 30 minutes at temperature of $80^{\circ} \mathrm{C}$. After that, the solution of PEG-6000 and PVP was combined at respective amounts to get a solution containing $10 \%$ of PEG and PVP each. The mixture was agitated with magnetic stirring until the complete transparent and clear homogenous solution was obtained.

3.2. Preparation of Silver Nanoparticles. For $\mathrm{Ag}^{0}$ development, $25 \mathrm{~mL}$ of $0.1 \mathrm{M} \mathrm{AgNO}_{3}$ was added to same volume of PEG-PVP mixture solution. This solution was kept on water bath at $100^{\circ} \mathrm{C}$ for a specified duration until a pure yellow characteristic color of silver nanoparticle appeared.

3.3. Standard $\mathrm{Hg}^{2+}$ Solution Preparation. For $\mathrm{Hg}^{2+}$ standard solutions preparation, $10 \mathrm{~mL}$ of $1000 \mathrm{ppm}$ stock solution was diluted in $100 \mathrm{~mL}$ volumetric flask and added by distilled water up to the mark, to get $100 \mathrm{ppm} \mathrm{Hg}^{2+}$ solution. This stock standard solution was further diluted in distilled water to get $90,80,70,60,50,40,30,20,10,5$, and 1 ppm solutions. $1 \mathrm{~mL}$ of prepared nanoparticles was reacted with $3 \mathrm{~mL}$ of standard mercury solutions of different concentrations and change in absorbance was observed. Observations were made after 10 minutes for the complete amalgamation.

3.4. Sample Preparation. For making sample from seafood, muscle tissues of fish were teased fully and about $5 \mathrm{gm}$ of teased tissues was digested in concentrated $\mathrm{HNO}_{3}$. The solution was filtered using Whatman (Schleicher \& Schuell) $125 \mathrm{~mm}$ filter paper and then diluted to $25 \mathrm{~mL}$ volumetric flask by double distilled water. The sample solution was 10 times diluted in $25 \mathrm{~mL}$ volumetric flask by taking $2.5 \mathrm{~mL}$ of stock sample and diluted by distilled water. $1 \mathrm{~mL}$ of prepared nanoparticles was reacted with $3 \mathrm{~mL}$ of the final solution of different dilutions and change in absorbance was monitored. Observations were made after 10 minutes for the complete amalgamation.

\section{Results and Discussion}

4.1. Development and Characterizations of the Ag Nanoparticles. The SNPs were obtained through a reduction reaction of silver nitrate with PEG6000 solution in the presence of PVP as capping agent. The UV-vis absorption spectrum of asprepared SNPs is given in Figure 1. It shows a characteristic peak centered at $411 \mathrm{~nm}$ in the visible light area. Calculated according to Lambert-Beer's law, the extinction coefficients of the SNPs are about $4.46 \times 10^{3} \mathrm{M}^{-1} \mathrm{~cm}^{-1}$ (at $411 \mathrm{~nm}$ ), which can meet the demand of colorimetric sensing detection.

For developing an efficient method to prepare silver nanoparticles, parameters, such as heating time, precursor's 


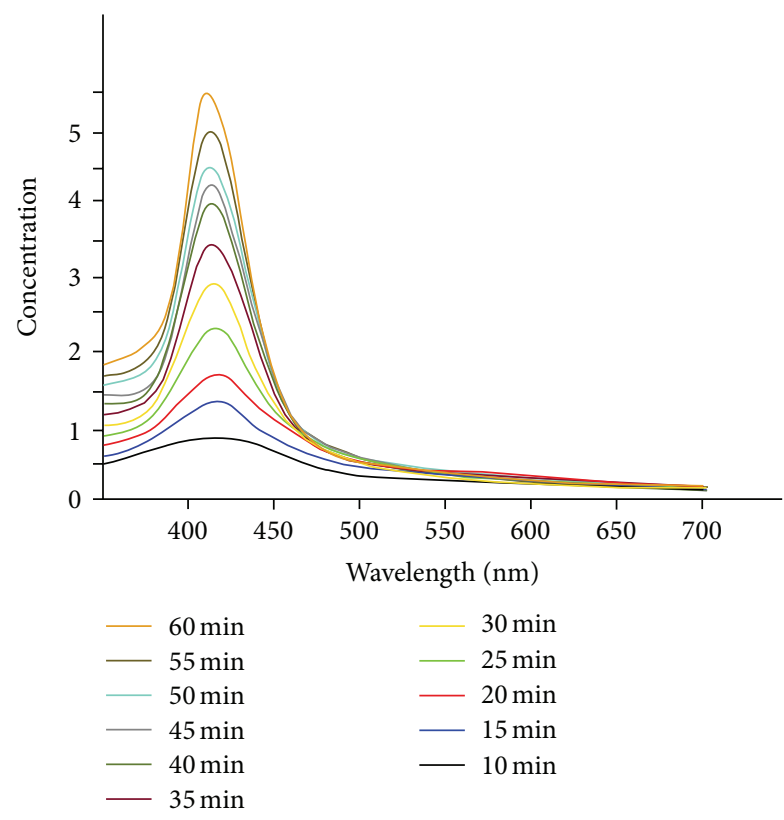

FiguRE 1: Spectral view for the formation of silver nanoparticles.

concentrations, and ratio, were extensively studied. Uniformity of shape and size has great influence on the experimental work. The formation of uniformly sized nanoparticles requires precise concentrations of $\mathrm{PVP}, \mathrm{PEG}$, and $\mathrm{AgNO}_{3}$ as well as heating time.

In the experiment, $\mathrm{AgNO}_{3}$ was reacted with PEG which caused the reduction of $\mathrm{Ag}^{+}$to $\mathrm{Ag}^{0}$. Since atomic form of any specie is very reactive, these newly formed $\mathrm{Ag}$ atoms react with each other and form aggregates of larger size, thus increasing their volume and decreasing their surface area. To inhibit their growth, polyvinylpyrrolidone was used as stabilizer cum capping agent. PVP seized the growth of Ag atom and restricted them to nanosized particles.

Since the reaction of $\mathrm{AgNO}_{3}$ and PEG is quite slow, to achieve high concentration of nanoparticles in short time, the reaction mixture was heated to about $90^{\circ} \mathrm{C}$ in water bath; for various intervals of time periods as 10 and 20 up to 90 minutes, and on each interval of ten minutes absorbance of SNPs was recorded Figure 1.

This figure shows the characteristic peak of silver nanoparticles at $411 \mathrm{~nm}$ due to surface plasmon resonance. The peak grows up as the time of heating was increased, and its intensity also increases due to increased concentration, uniformity of shape, and size of nanoparticles. The different researchers confirmed the presence of nanostructured silver particles having surface plasmon resonance peak around $380 \mathrm{~nm}$ to $424 \mathrm{~nm}$ by TEM, XRD, and SEM [20, 21], thus conforming the presence of silver nanoparticles in the solution.

Figure 2 shows that the absorbance of nanoparticles increases at $411 \mathrm{~nm}$ as the time of heating is increased. These two figures confirm the formation and increase in the concentration of nanoparticles as the heating time increases. Thus, rate of reaction was calculated from the slope of line in

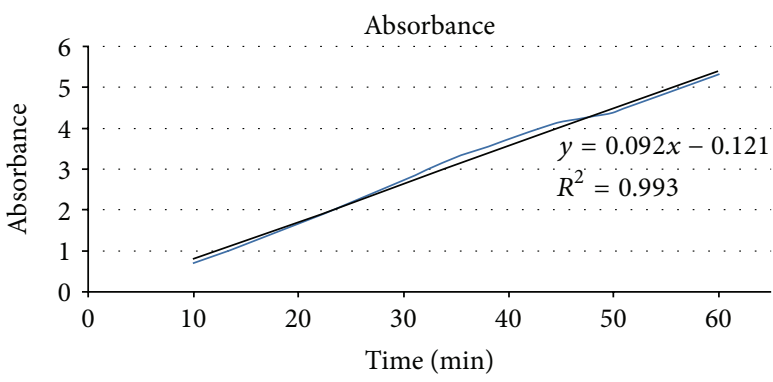

FIgURE 2: Absorbance versus time domain for the formation of nanoparticles at $411 \mathrm{~nm}$.

Figure 2 and was found to be $0.092 \mathrm{abs} / \mathrm{min}(y=0.092 x-$ $\left.0.121, R^{2}=0.993\right)$. This confirms that the higher is the heating time the higher will be the production of nanoparticles up to certain limits, until an optimal heating time was achieved, that is, 60 minutes in our experiment, and after that the further heating decreased the SNPs concentration as determined by the absorbance.

Finally, it was found that absorbance is directly related to the concentration of nanoparticles; by Lambert-Beer's Law, absorptivity value was found to be $4.46 \times 10^{3} \mathrm{M}^{-1} \cdot \mathrm{cm}^{-1}$.

Further work can be done in this regard on the basis of different temperatures affecting the rate of formation of nanoparticles and different concentrations of PEG and $\mathrm{AgNO}_{3}$ affecting the rate of nanoparticles formation as well as the effect of different concentrations of PVP on the size, shape and uniformity of nanoparticles.

4.2. Sensing and Detection of $\mathrm{Hg}^{2+}$. After the formation of stabilized nanoparticles, the second stage was to observe the reaction of mercury with these nanoparticles. Since standard electrode potential of $\mathrm{Ag}^{+} / \mathrm{Ag}$ is $0.80 \mathrm{~V}$ and $\mathrm{Hg}^{2+} / \mathrm{Hg}$ is $0.85 \mathrm{~V}$, it is expected that a redox reaction can occur between zerovalent silver and $\mathrm{Hg}^{2+}$. Thus, in this work, the sensitivity of silver nanoparticles toward $\mathrm{Hg}^{2+}$ was identified by $\mathrm{UV}$-vis absorption spectra.

Reaction time of amalgamation was tested by addition of different concentration of mercury to the constant amount of nanoparticles. Change in absorbance was monitored over a period of time after the addition of mercury; it was apparent that the process of amalgamation was almost complete after 10 minutes. Therefore, further treatment of mercury determination was abandoned after 10 minutes, and absorbance was monitored. As the different concentration of mercury was treated with constant amount of nanoparticles, decrease in the absorbance and change in $\lambda_{\max }$ of the silver nanoparticles were observed; blue shifting of nanoparticles was observed Figures 3 and 5 .

Blue shifting was so much small that instrument was unable to formulate any reading that can be used to make any direct or linear relation. However, change in the absorbance at $\lambda_{\text {max }}(411 \mathrm{~nm})$ was found to be linearly correlated with the amount of mercury treated with SNPs as shown in Figures 4 and $6\left(y=0.023 x-0.872, R^{2}=0.986\right)$. Detection limit of the method was found to be $0.884 \mathrm{ppm}$. Linear relation of change in silver nanoparticles concentration and so as the absorbance 


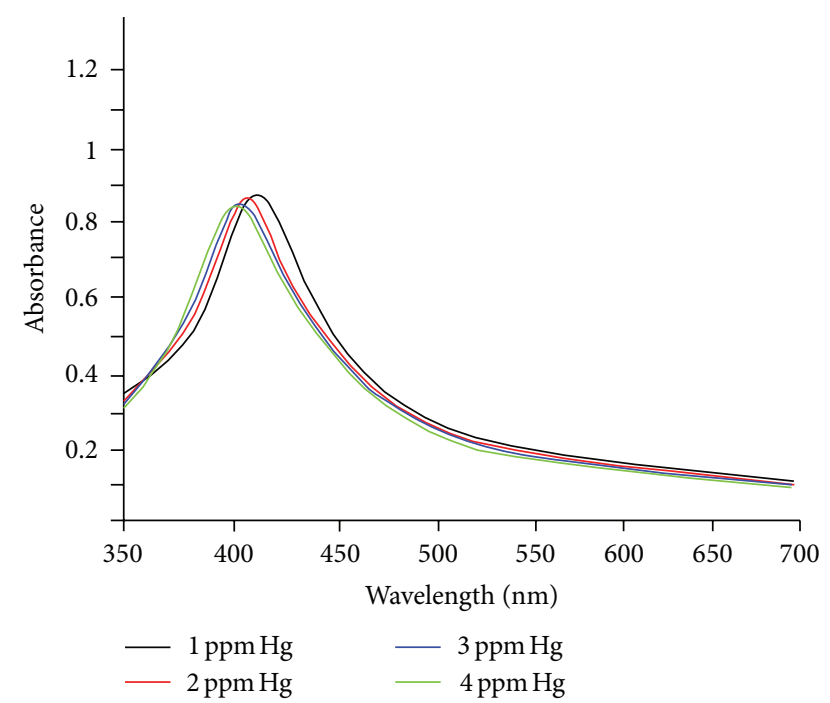

Figure 3: Effect of different concentration of mercury on the $\lambda_{\max }$ and absorbance of silver nanoparticles.

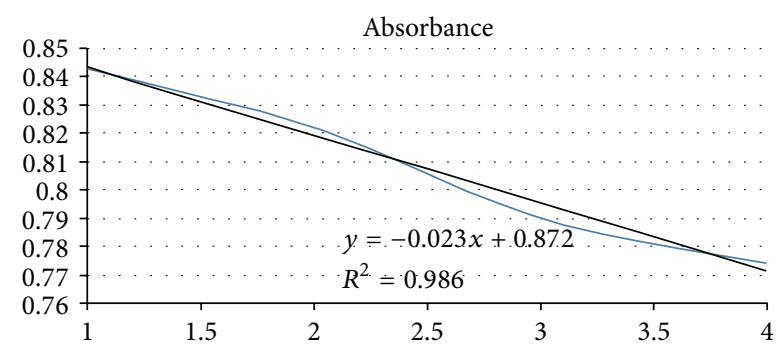

FIGURE 4: Change in absorbance of silver nanoparticles at $411 \mathrm{~nm}$ as mercury increases.

with mercury concentration proves to be vital in the mercury determination.

4.3. Detection of $\mathrm{Hg}^{2+}$ in Seafoods. Cautions on the mercury concentration in seafood have sparkled the consumers distress about fish utilization. The mercury content in fish has been shown to vary widely depending on factors such as fish species, size, place in the food chain, and location of habitat. The same species of fish tested in separate parts of the world have been shown to contain different levels of mercury [22].

The linear relation as proved above (Figures 4 and 6) was used for the determination of mercury content in seafood fish samples. The digested fish sample was diluted and then reacted with silver nanoparticles and the effect was studied. Mercury in the diluted fish sample was found to be in between 7 and $9 \mathrm{ppm}$. The results shows very high mercury content of mercury in fish samples, above the EPA criterion of $0.3 \mathrm{mg} / \mathrm{Kg}$ (equivalent to 0.3 parts per million, $\mathrm{ppm}$ ) set to protect public health [23]. Dilution factor was used for reporting the real mercury content in ppm as the standards set by EPA and FDA. These values are far beyond the safe limits of mercury as given by EPA and FDA. These results are alarming for the government to take an immediate action on treating the industrial, agricultural, and domestic wastes in proper

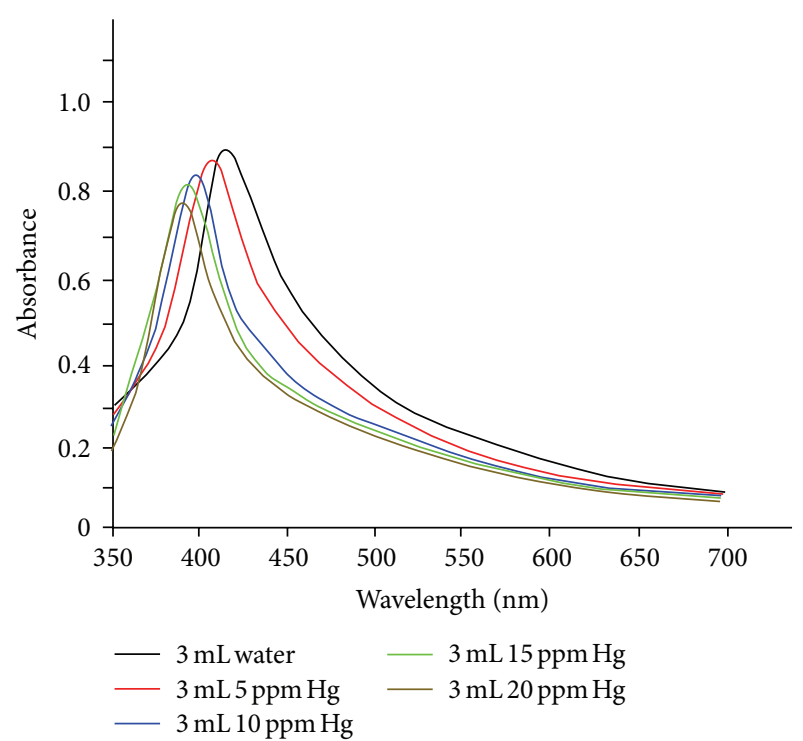

FIGURE 5: Effect of mercury on $\lambda_{\max }$ and absorbance of silver nanoparticles.

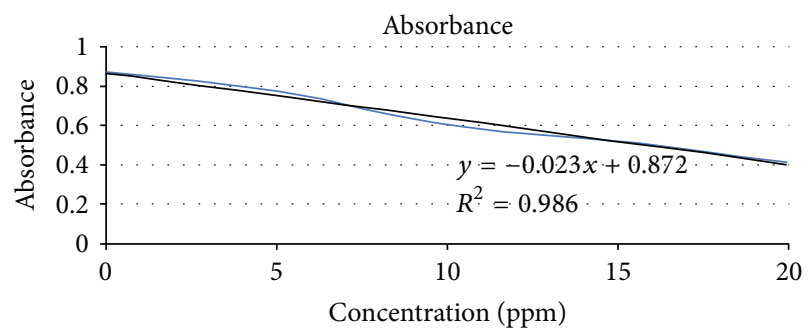

FiguRE 6: Effect of mercury addition on absorbance of silver nanoparticles at $411 \mathrm{~nm}$.

manner in order to protect fresh and marine life. This will in return protect the people from having that much high dose of mercury in seafoods and adverse health effects.

\section{Conclusion}

In conclusion, the PVP-stabilized Ag nanoparticles were obtained via a reduction approach by PEG. $\mathrm{Hg}^{2+}$ ions in aqueous media were recognized by these nanoparticles via a colorimetric method with high selectivity and sensitivity. This approach relies on the simple redox reaction between $\mathrm{Ag}$ nanoparticles and $\mathrm{Hg}^{2+}$ ion solution. The concentration of $\mathrm{Hg}^{2+}$ can be determined by the change of the intensity of the silver absorbance peak at room temperature. The easy synthesis, high stability, and high water solubility of the PVP-stabilized Ag nanoparticle probes allow a reliable assay performed in aqueous environments to determine the mercury contamination quantitatively.

\section{Conflict of Interests}

It is hereby declared by the authors that there is no conflict of interests and that the research work was not sponsored partially or fully by anyone in any sense. 


\section{References}

[1] C. Sönnichsen, B. M. Reinhard, J. Liphardt, and A. P. Alivisatos, "A molecular ruler based on plasmon coupling of single gold and silver nanoparticles," Nature Biotechnology, vol. 23, no. 6, pp. 741-745, 2005.

[2] H. H. Harris, I. J. Pickering, and G. N. George, "The chemical form of mercury in fish," Science, vol. 301, no. 5637, p. 1203, 2003.

[3] P. Grandjean, P. Weihe, R. F. White, and F. Debes, "Cognitive performance of children prenatally exposed to "safe" levels of methylmercury," Environmental Research, vol. 77, no. 2, pp. 165$172,1998$.

[4] S. Yoon, A. E. Albers, A. P. Wong, and C. J. Chang, "Screening mercury levels in fish with a selective fluorescent chemosensor," Journal of the American Chemical Society, vol. 127, no. 46, pp. 16030-16031, 2005.

[5] J. Wang and B. Liu, "Highly sensitive and selective detection of $\mathrm{Hg}^{2+}$ in aqueous solution with mercury-specific DNA and Sybr Green I," Chemical Communications, no. 39, pp. 4759-4761, 2008.

[6] X.-J. Zhu, S.-T. Fu, W.-K. Wong, J.-P. Guo, and W.-Y. Wong, "A near-infrared-fluorescent chemodosimeter for mercuric ion based on an expanded porphyrin," Angewandte Chemie International Edition, vol. 45, no. 19, pp. 3150-3154, 2006.

[7] J. V. Ros-Lis, M. D. Marcos, R. Mártinez-Máñez, K. Rurack, and J. Soto, "A regenerative chemodosimeter based on metalinduced dye formation for the highly selective and sensitive optical determination of $\mathrm{Hg}^{2+}$ ions," Angewandte Chemie International Edition, vol. 44, no. 28, pp. 4405-4407, 2005.

[8] Y.-K. Yang, K.-J. Yook, and J. Tae, "A rhodamine-based fluorescent and colorimetric chemodosimeter for the rapid detection of $\mathrm{Hg}^{2+}$ ions in aqueous media," Journal of the American Chemical Society, vol. 127, no. 48, pp. 16760-16761, 2005.

[9] X. Guo, X. Qian, and L. Jiat, "A highly selective and sensitive fluorescent chemosensor for $\mathrm{Hg}^{2+}$ in neutral buffer aqueous solution," Journal of the American Chemical Society, vol. 126, no. 8, pp. 2272-2273, 2004.

[10] S. Yoon, E. W. Miller, Q. He, P. H. Do, and C. J. Chang, "A bright and specific fluorescent sensor for mercury in water, cells, and tissue," Angewandte Chemie International Edition, vol. 46, no. 35, pp. 6658-6661, 2007.

[11] A. Caballero, R. Martínez, V. Lloveras et al., "Highly selective chromogenic and redox or fluorescent sensors of $\mathrm{Hg}^{2+}$ in aqueous environment based on 1,4-disubstituted azines," Journal of the American Chemical Society, vol. 127, no. 45, pp. 15666-15667, 2005.

[12] E. Coronado, J. R. Galán-Mascarós, C. Martí-Gastaldo et al., "Reversible colorimetric probes for mercury sensing," Journal of the American Chemical Society, vol. 127, no. 35, pp. 12351-12356, 2005.

[13] Y. Zhao and Z. Zhong, "Tuning the sensitivity of a foldamerbased mercury sensor by its folding energy," Journal of the American Chemical Society, vol. 128, no. 31, pp. 9988-9989, 2006.

[14] J.-S. Lee, M. S. Han, and C. A. Mirkin, "Colorimetric detection of mercuric ion $\left(\mathrm{Hg}^{2+}\right)$ in aqueous media using DNAfunctionalized gold nanoparticles," Angewandte Chemie International Edition, vol. 46, no. 22, pp. 4093-4096, 2007.

[15] G. K. Darbha, A. K. Singh, U. S. Rai, E. Yu, H. Yu, and P. C. Ray, "Selective detection of mercury (II) ion using nonlinear optical properties of gold nanoparticles," Journal of the American Chemical Society, vol. 130, no. 25, pp. 8038-8043, 2008.
[16] D. Li, A. Wieckowska, and I. Willner, "Optical analysis of $\mathrm{Hg}^{2+}$ ions by oligonucleotide-gold-nanoparticle hybrids and DNAbased machines," Angewandte Chemie International Edition, vol. 47, no. 21, pp. 3927-3931, 2008.

[17] Y. Fan, Z. Liu, L. Wang, and J. Zhan, "Synthesis of starchstabilized $\mathrm{Ag}$ nanoparticles and $\mathrm{Hg}^{2+}$ recognition in aqueous media," Nanoscale Research Letters, vol. 4, no. 10, pp. 1230-1235, 2009.

[18] R. K. Bera, A. K. Das, and C. R. Raj, "Enzyme-cofactorassisted photochemical synthesis of Ag nanostructures and shape-dependent optical sensing of $\mathrm{Hg}$ (II) ions," Chemistry of Materials, vol. 22, no. 15, pp. 4505-4511, 2010.

[19] S. Schultz, D. R. Smith, J. J. Mock, and D. A. Schultz, "Singletarget molecule detection with nonbleaching multicolor optical immunolabels," Proceedings of the National Academy of Sciences of the United States of America, vol. 97, no. 3, pp. 996-1001, 2000.

[20] J.-J. Zhu, X.-H. Liao, X.-N. Zhao, and H.-Y. Chen, "Preparation of silver nanorods by electrochemical methods," Materials Letters, vol. 49, no. 2, pp. 91-95, 2001.

[21] D. D. Evanoff Jr. and G. Chumanov, "Synthesis and optical properties of silver nanoparticles and arrays," ChemPhysChem, vol. 6, no. 7, pp. 1221-1231, 2005.

[22] M. T. Morrissey, R. Rasmussen, and T. Okada, "Mercury content in pacific troll-caught albacore tuna (Thunnus alalunga)," Journal of Aquatic Food Product Technology, vol. 13, no. 4, pp. 41-52, 2004.

[23] S. L. Blanco, J. C. González, and J. M. Vieites, "Mercury, cadmium and lead levels in samples of the main traded fish and shellfish species in Galicia, Spain," Food Additives and Contaminants B, vol. 1, no. 1, pp. 15-21, 2008. 

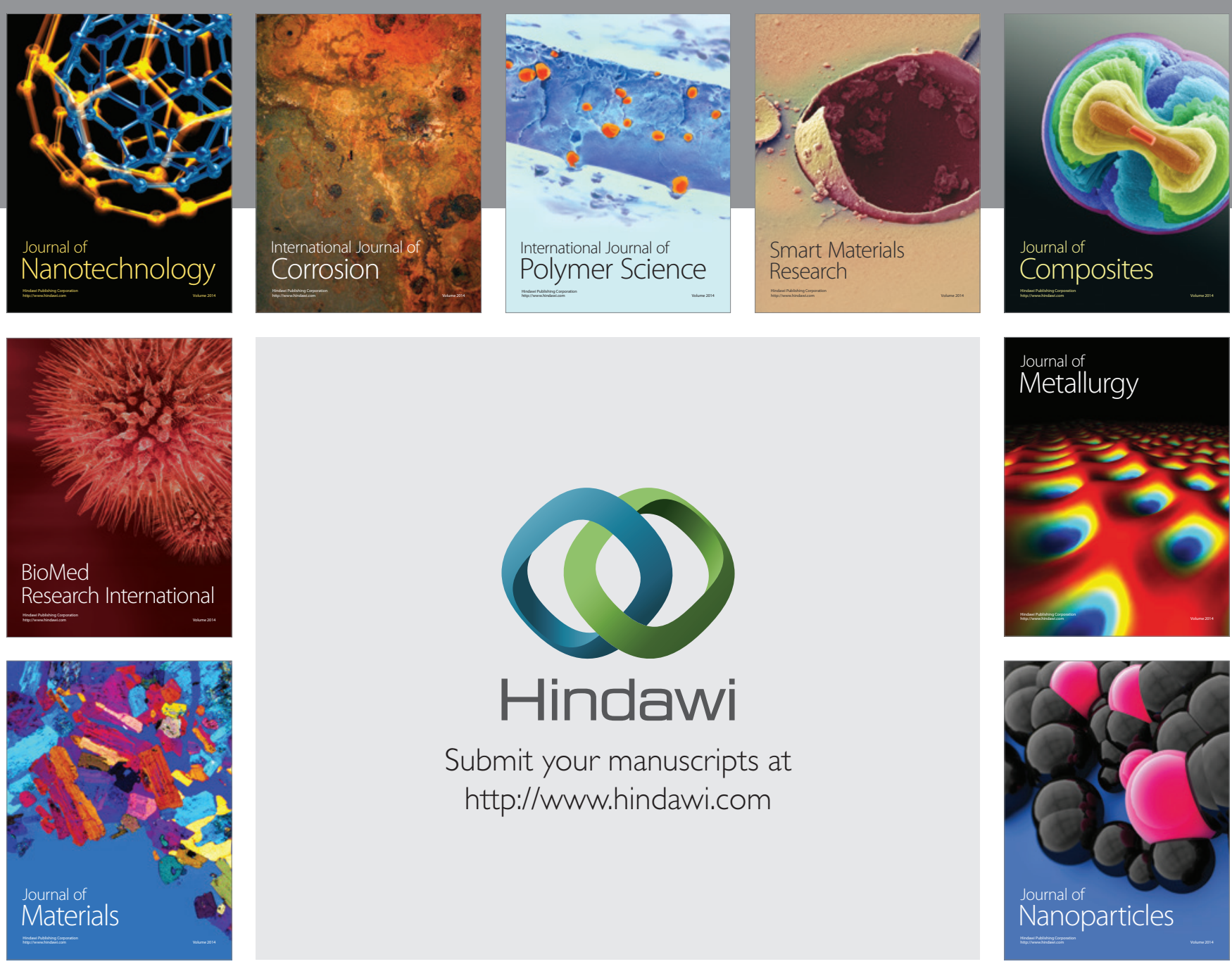

Submit your manuscripts at http://www.hindawi.com
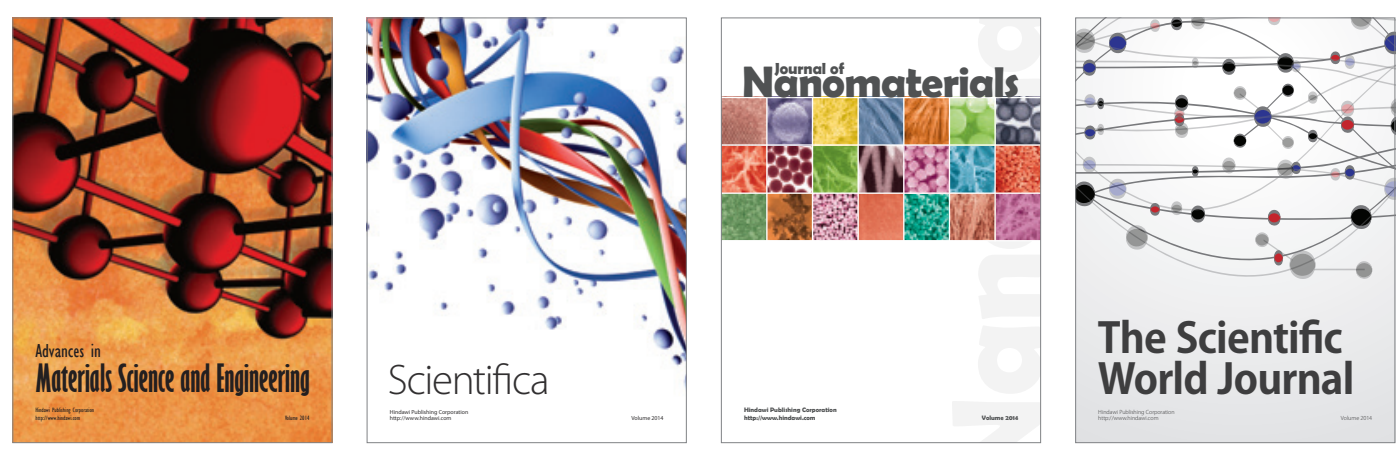

\section{The Scientific World Journal}
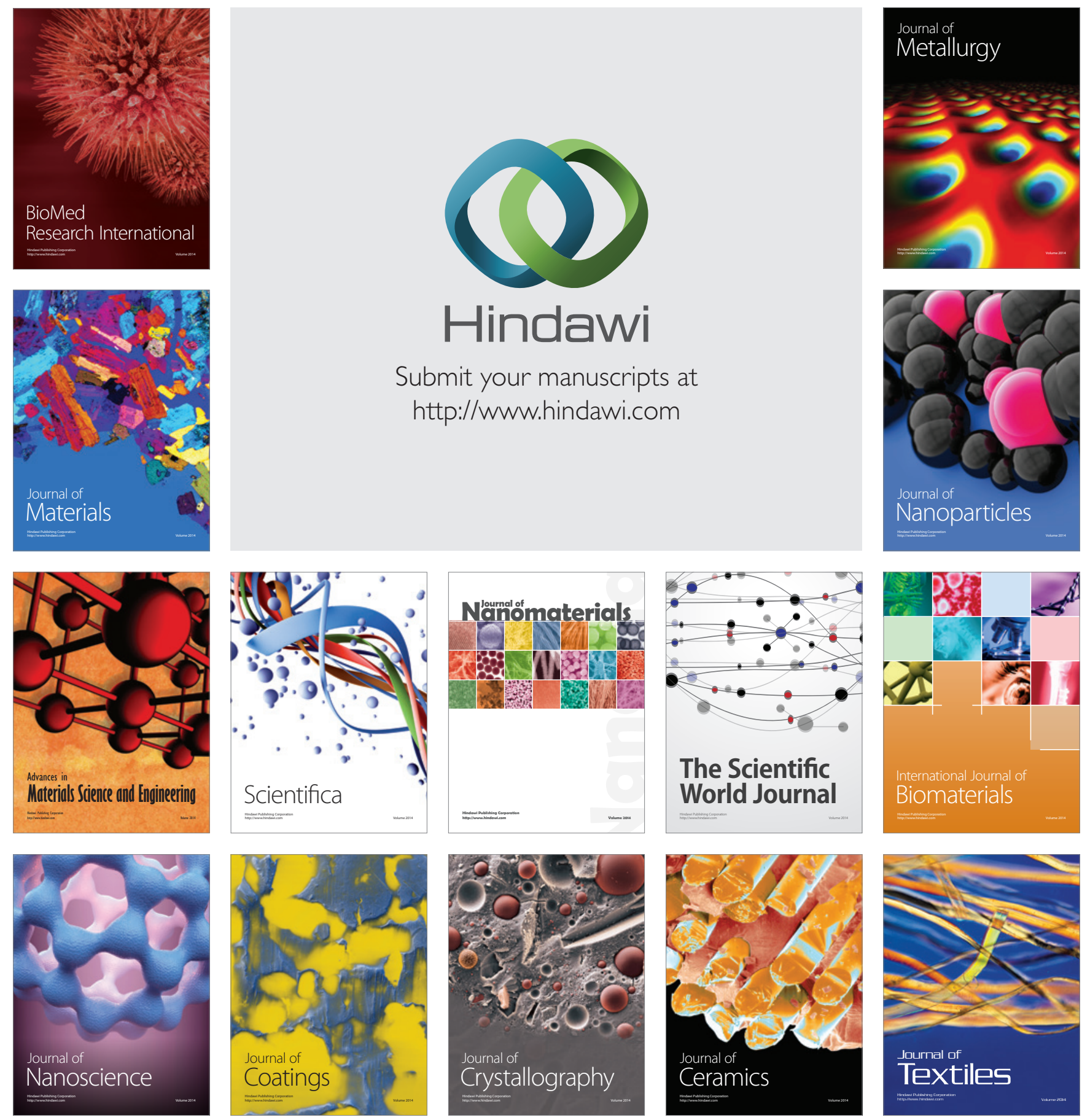